\title{
Public Preferences for Allocation Principles for Scarce Medical Resources in the COVID-19 Pandemic in Korea: Comparisons With Ethicists' Recommendations
}

\author{
Ji-Su Lee ${ }^{1}$, Soyun Kim², Young Kyung Do ${ }^{1,2}$ \\ ${ }^{1}$ Department of Health Policy and Management, Seoul National University College of Medicine, Seoul, Korea; ${ }^{2}$ Institute of Health Policy and \\ Management, Seoul National University Medical Research Center, Seoul, Korea
}

Objectives: The purpose of this study was to investigate public preferences regarding allocation principles for scarce medical resources in the coronavirus disease 2019 (COVID-19) pandemic, particularly in comparison with the recommendations of ethicists.

Methods: An online survey was conducted with a nationally representative sample of 1509 adults residing in Korea, from November 2 to 5, 2020. The degree of agreement with resource allocation principles in the context of the medical resource constraints precipitated by the COVID-19 pandemic was examined. The results were then compared with ethicists' recommendations. We also examined whether the perceived severity of COVID-19 explained differences in individual preferences, and by doing so, whether perceived severity helps explain discrepancies between public preferences and ethicists' recommendations.

Results: Overall, the public of Korea agreed strongly with the principles of "save the most lives," "Koreans first," and "sickest first," but less with "random selection," in contrast to the recommendations of ethicists. "Save the most lives" was given the highest priority by both the public and ethicists. Higher perceived severity of the pandemic was associated with a greater likelihood of agreeing with allocation principles based on utilitarianism, as well as those promoting and rewarding social usefulness, in line with the opinions of expert ethicists.

Conclusions: The general public of Korea preferred rationing scarce medical resources in the COVID-19 pandemic predominantly based on utilitarianism, identity and prioritarianism, rather than egalitarianism. Further research is needed to explore the reasons for discrepancies between public preferences and ethicists' recommendations.

Key words: Resource allocation, Health care rationing, COVID-19, Empirical ethics

\section{INTRODUCTION}

Received: June 15, 2021 Accepted: August 9, 2021

Corresponding author: Young Kyung Do

Department of Health Policy and Management, Seoul National

University College of Medicine, 103 Daehak-ro, Jongno-gu,

Seoul 03080, Korea

E-mail: ykd089@snu.ac.kr

This is an Open Access article distributed under the terms of the Creative Commons Attribution Non-Commercial License (https://creativecommons.org/licenses/by$\mathrm{nc} / 4.0 /$ ) which permits unrestricted non-commercial use, distribution, and reproduction in any medium, provided the original work is properly cited.
The rapid increase in demand for medical resources caused by the coronavirus disease 2019 (COVID-19) pandemic has resulted in shortages of various medical resources such as masks, vaccines, hospital beds, and ventilators [1]. In Korea, there was a temporary shortage of facial masks in the early phase of $\mathrm{CO}$ VID-19, when people often had to queue up in long lines in front of pharmacies to purchase facial masks on the day of the week corresponding to their year of birth, a rationing system 
swiftly instituted by the government [2]. On a graver note, some patients diagnosed with COVID-19 died while waiting for admission because no hospital beds were made available for them [3]. The situation of resource shortage inevitably leads to the need to ration scarce medical resources. Although the rationing of medical resources has always been done explicitly or implicitly, more explicit resource allocation principles and guidelines are needed in a pandemic situation [4-6].

Key resource allocation principles have emerged from the literature. In a widely cited article in the COVID-19 context [7], Emanuel and colleagues discussed 8 allocation principles. The value of maximizing benefits is most important, and the "save the most lives" principle takes precedence over "save the most life-years." Next, the principle of "priority to those who are likely to make relevant contributions" can be used. Among people with a similar prognosis, equality should be considered using the "random selection" principle, not "first-come, first-served" The principle of "priority to those who have made relevant contributions" can be used when other factors are equal, and the principles of "sickest first" and "youngest first" can be used when they align with maximizing benefits. These principles proposed in the COVID-19 context are different from those presented in Emanuel's previously published paper regarding rationing scarce medical resources in general situations [8]. In this earlier paper, the same 8 principles were reviewed and part of them were incorporated into a multi-principle allocation system called the "complete lives system." In this system, the "priority to those who are likely to make relevant contributions" principle was not included, with the caveat that it is a principle that could be used in a pandemic. A comparison of the 8 allocation principles in the 2 papers reveals that, in a pandemic such as COVID-19, greater priority is given to the principles based on utilitarianism. Other ethicists have also argued that the case for rationing based on utilitarianism can be strengthened in a pandemic $[9,10]$.

The public's view, however, appears to be different from that of ethicists. In a United Kingdom study in which the public was asked to rank the 8 principles, the public viewed "sickest first" and "youngest first" as the second and third most important principles, while ethicists argued that these principles can only be used when they align with maximizing benefits [11]. In a United States study, the general public's opinion was also markedly different from the recommendations of ethicists [12]. These differences between the general public and expert ethicists call for the need to further investigate the public's moral preferences regarding the allocation principles for scarce medical resources in the COVID-19 pandemic. Doing so is necessary because moral value judgments should not be monopolized by ethicists, who tend to emphasize the coherence of arguments, which is not a sufficient condition for justice $[13,14]$. When rationing policies or guidelines are developed and implemented, the public is most affected by them. Therefore, in terms of democratic legitimacy, efforts to identify and reflect the public's values are critical [15]. Another reason for the need to investigate the public's values is that, since medical resource allocation policies or guidelines involve the decision of who shall live and die, the public's receptivity would be low if they consider such policies or guidelines to be unjust [15]. In Italy, for example, the use of medical resources for the elderly was withheld at a certain point of the COVID-19 pandemic, which resulted in fierce public debates and criticism [16].

This study investigated public preferences regarding the allocation principles for scarce medical resources in the COVID19 pandemic in Korea, particularly in comparison with the recommendations of ethicists. Although ethical arguments have been made for the rationing of scarce medical resources in the COVID-19 pandemic, both in a specific context and in general [5,17-20], no studies have yet empirically investigated the public's preferences for resource allocation principles in Korea. Since there is heterogeneity in moral preferences for allocation principles among different countries [21], this study can make a useful contribution to the rapidly growing international literature on the public's view on resource allocation principles in pandemic conditions. In addition to presenting the general public's preferences for resource allocation principles, we compare them with the recommendations of expert ethicists for pandemic situations in order to explore important differences. Furthermore, we examined whether this discrepancy between the public and experts in the COVID-19 pandemic can be explained, at least partially, by the perceived severity of the COVID-19 pandemic. To this end, we specifically examined whether a higher perceived severity of the COVID-19 pandemic was associated with a greater degree of agreement with principles based on utilitarianism. If this is the case, part of the differences in resource allocation principles in the COVID-19 pandemic between the public and ethicists could be attributed to the lower perceived severity in some fraction of the population. 


\section{METHODS}

\section{Participants and Sampling}

The survey in this study was conducted from November 2 to 5,2020 . The subjects were adults aged 19 years to 69 years residing in Korea. The study used a web-based online survey with a proportional quota-based sample based on gender, age group (19-29, 30-39, 40-49, 50-59, 60-69), and region (17 provinces). The proportional quota was determined according to the resident registration population standards announced by the Ministry of Public Administration and Security as of September 2020. The survey was administered by a large commercial market research company maintaining about 540000 people as its own panel. Initially, 8903 people were sent invitation letters via email or text messages. Of those who received an invitation, 1935 accepted (response rate, 18.6\%). Of those who accepted, 426 (22.0\%) did not complete the survey: 32 (1.7\%) did not satisfy the age criteria, 120 (6.2\%) were allocated to quotas that had already been filled, 271 (14.0\%) had incomplete responses, and $3(0.2 \%)$ had technical problems. The remaining 1509 participants completed the survey (completion rate, $78.0 \%$ ) and constituted our final sample. The general characteristics of the respondents are presented in Table 1 (Supplementary Material 1).

\section{Questionnaire}

We developed a questionnaire to measure public preferences regarding the allocation principles for scarce medical resources in the COVID-19 pandemic. The overarching question read as follows: "In a pandemic situation such as COVID-19, medical resources such as masks, vaccines, hospital beds, and ventilators can become scarce compared to their need. We would like to ask your opinion on rationing scarce medical resources in the context of such a shortage of medical resources. To what extent do you agree with the comments below?"Then, an explanation of the 10 allocation principles was presented, and the degree of agreement was chosen on a 5-point Likert scale. Among the 10 allocation principles, 8 were derived from Emanuel et al. [7]. We also chose to include 2 additional principles: one is based on identity-based allocation and the other on luck-egalitarianism. It is generally considered that identitybased allocation cannot be morally justified [15], and there are different views and debates on the moral justification of allocation principles based on luck-egalitarianism [22,23]. The allocation principles and their explanations used in the survey
Table 1. General characteristics of respondents $(n=1,509)$

\begin{tabular}{|c|c|c|}
\hline Characteristics & $\begin{array}{l}\text { Unweighted } \\
\text { (n) }\end{array}$ & $\begin{array}{c}\text { Weighted } \\
\text { proportion (\%) }\end{array}$ \\
\hline \multicolumn{3}{|l|}{ Gender } \\
\hline Men & 764 & 50.8 \\
\hline Women & 745 & 49.2 \\
\hline \multicolumn{3}{|l|}{ Age (y) } \\
\hline $19-29$ & 292 & 19.5 \\
\hline $30-39$ & 281 & 18.4 \\
\hline $40-49$ & 332 & 22.0 \\
\hline $50-59$ & 344 & 22.7 \\
\hline $60-69$ & 260 & 17.4 \\
\hline \multicolumn{3}{|l|}{ Marital status } \\
\hline Never married & 479 & 31.8 \\
\hline Married, living together & 919 & 60.9 \\
\hline Separated, divorced, or widowed & 111 & 7.4 \\
\hline \multicolumn{3}{|l|}{ Education level } \\
\hline High school & 663 & 44.2 \\
\hline Vocational college & 171 & 11.2 \\
\hline College or more & 675 & 44.6 \\
\hline \multicolumn{3}{|l|}{ Monthly household income $\left(10^{4} \mathrm{KRW}\right)$} \\
\hline$\leq 200$ & 335 & 22.3 \\
\hline $201-400$ & 545 & 36.1 \\
\hline $401-600$ & 379 & 25.1 \\
\hline$>600$ & 250 & 16.5 \\
\hline \multicolumn{3}{|l|}{ Religiosity } \\
\hline Religious & 635 & 42.1 \\
\hline Non-religious & 874 & 57.9 \\
\hline \multicolumn{3}{|l|}{ Political orientation } \\
\hline Progressive (left) & 93 & 6.2 \\
\hline Moderate progressive & 397 & 26.0 \\
\hline Moderate & 703 & 46.7 \\
\hline Moderate conservative & 233 & 15.5 \\
\hline Conservative (right) & 83 & 5.5 \\
\hline \multicolumn{3}{|l|}{ Chronic disease or disability } \\
\hline Yes & 415 & 27.6 \\
\hline No & 1094 & 72.4 \\
\hline \multicolumn{3}{|l|}{ Self-rated health } \\
\hline Very poor & 15 & 1.0 \\
\hline Poor & 218 & 14.4 \\
\hline Fair & 797 & 52.9 \\
\hline Good & 395 & 26.1 \\
\hline Very good & 84 & 5.6 \\
\hline \multicolumn{3}{|c|}{ Perceived severity of the COVID-19 pandemic } \\
\hline None & 3 & 0.2 \\
\hline Mild & 23 & 1.5 \\
\hline Moderate & 166 & 11.1 \\
\hline Severe & 849 & 56.1 \\
\hline Very severe & 468 & 31.0 \\
\hline
\end{tabular}

KRW, Korean won; COVID, coronavirus disease 2019 
Table 2. Allocation principles and questionnaire used in the survey

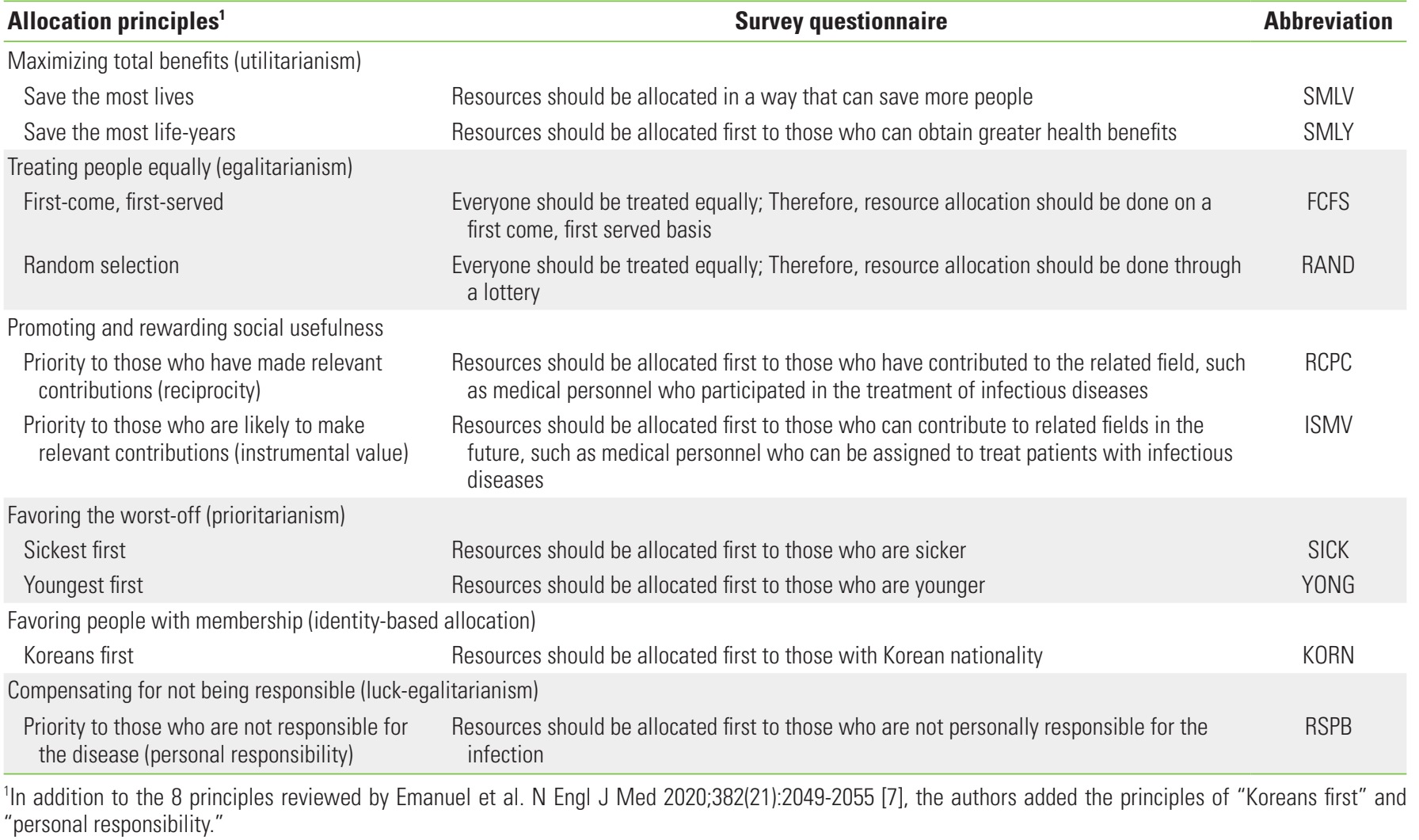

are presented in Table 2 (Korean version in Supplementary Material 2). The questionnaire also included questions on the perceived severity of COVID-19 and individual characteristics (e.g., gender, age, religiosity, political orientation, socioeconomic status, health status), since these factors can have effects on people's ethical preferences [24-27].

\section{Statistical Analysis}

We calculated descriptive statistics for the public's degree of agreement with each allocation principle, taking the post-stratification weights into account. To examine whether there were significant differences in preferences between allocation principles, the 10 allocation principles were grouped into pairs and the differences were compared using the paired $t$-test. Based on the results, we determined the order of preferences among the allocation principles. Then, we compared the results with the widely agreed-upon recommendations of ethicists [7].

To examine differences in preferences for the allocation principles according to the perceived severity of COVID-19, ordered logistic regression was performed for each allocation principle. For the principles of "save the most lives," "save the most life-years," "reciprocity," "instrumental value," "sickest first," "youngest first," and "Koreans first," the number of people who responded "strongly disagree" and "disagree" were exceedingly small, forcing us to combine them into one category for analysis. For the perceived severity of COVID-19, "none," "mild," and "moderate" were combined into a single category ("not severe") for the same reason. We controlled for gender, age, marital status, education level, household income, religiosity, political orientation, chronic disease or disability, and self-rated health in the analysis (Supplementary Material 3). Post-stratification weights were not applied because the purpose of this analysis was to explore the association between respondents' perceived severity of the COVID-19 pandemic and their preferences for allocation principles. All statistical analyses were conducted using Stata version 16.0 (StataCorp , College Station, TX, USA), and statistical significance was interpreted as a $p$-value less than 0.05 and 0.01 .

\section{Ethics Statement}

Ethical approval was obtained from the Institutional Review Board (IRB) of Seoul National University Hospital before the start of the study (IRB No. C-1904-016-1025). 


\section{RESULTS}

The degree of agreement with each principle, in terms of mean values, was highest for "save the most lives," followed in descending order by "'Koreans first," "sickest first," "reciprocity," "youngest first," "instrumental value," "save the most life-years," "personal responsibility," "first-come, first-served," and "random selection" (lowest) (Figure 1). The only principle with a higher percentage of disagreement than agreement was "random se-
lection."There were statistically significant differences $(p<0.01)$ between paired principles, except for between "reciprocity" and "youngest first," and between "instrumental value" and "save the most life-years" (Supplementary Material 4). Based on these results, we classified the public's preferences for the 10 allocation principles into 8 priorities (Figure 2).

Marked differences were observed between public preferences and ethicists' recommendations for the allocation principles (Figure 2). While "save the most life-years" was deemed

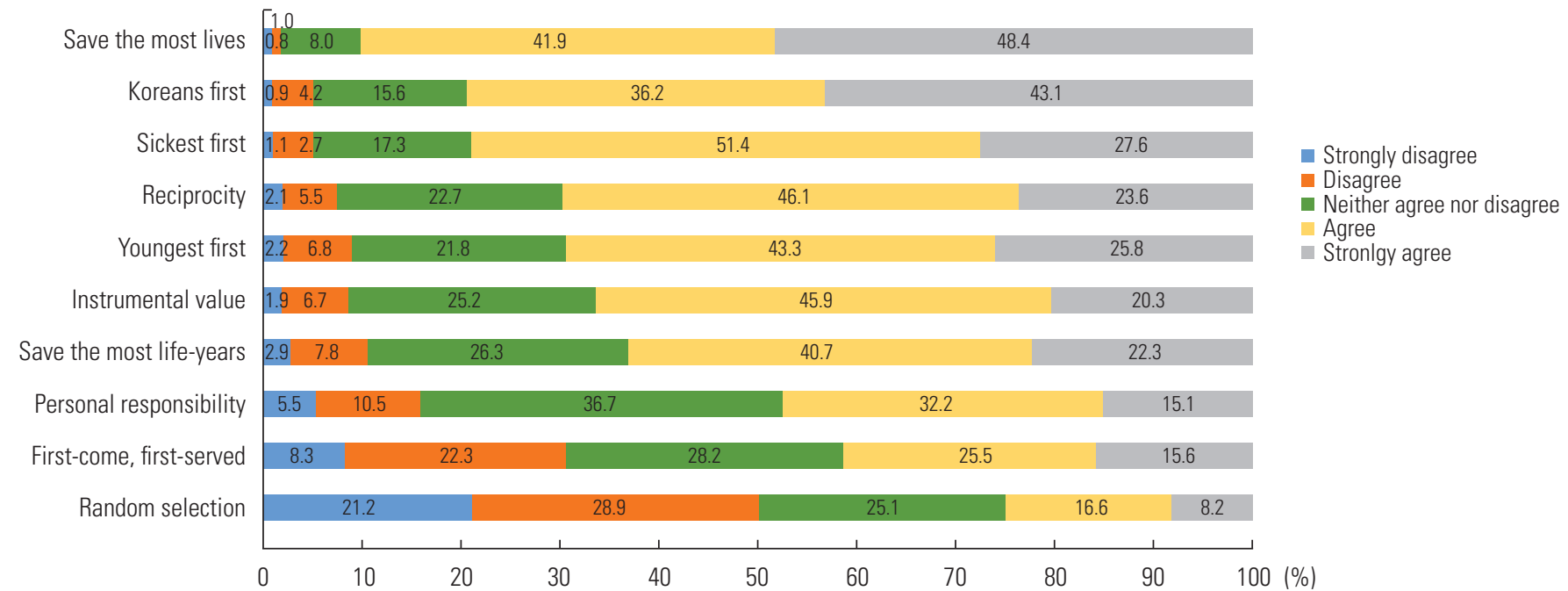

Figure 1. Degree of agreement on allocation principles. Post-stratification weights are applied. The order is based on the mean value of agreement calculated with 1 for strongly disagree and 5 for strongly agree.

Ethicists' recommendations

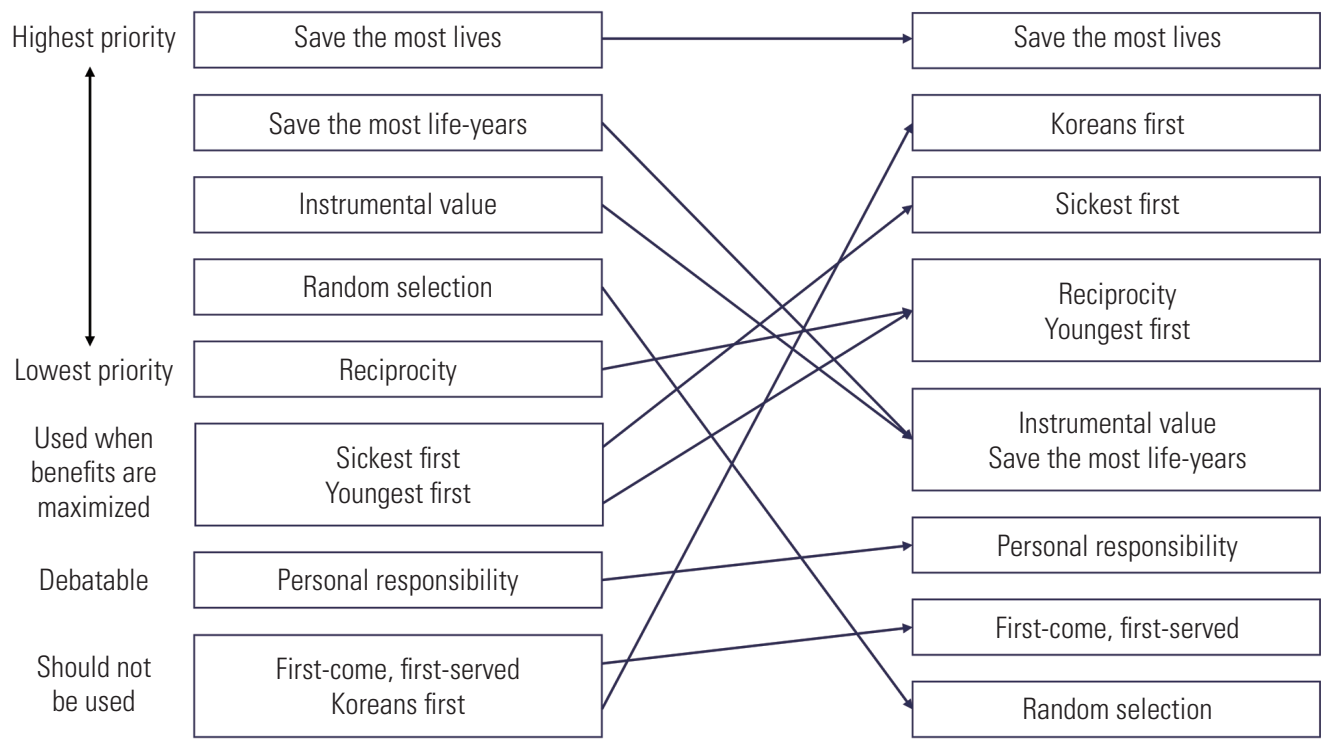

Highest agreement

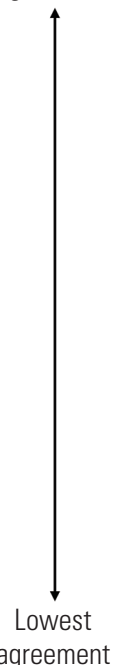

Figure 2. Differences between ethicists' recommendations and public preferences on allocation principles. Ethicists' recommendations are modified by the author based on Emanuel et al. N Engl J Med 2020;382(21):2049-2055 [7]. 


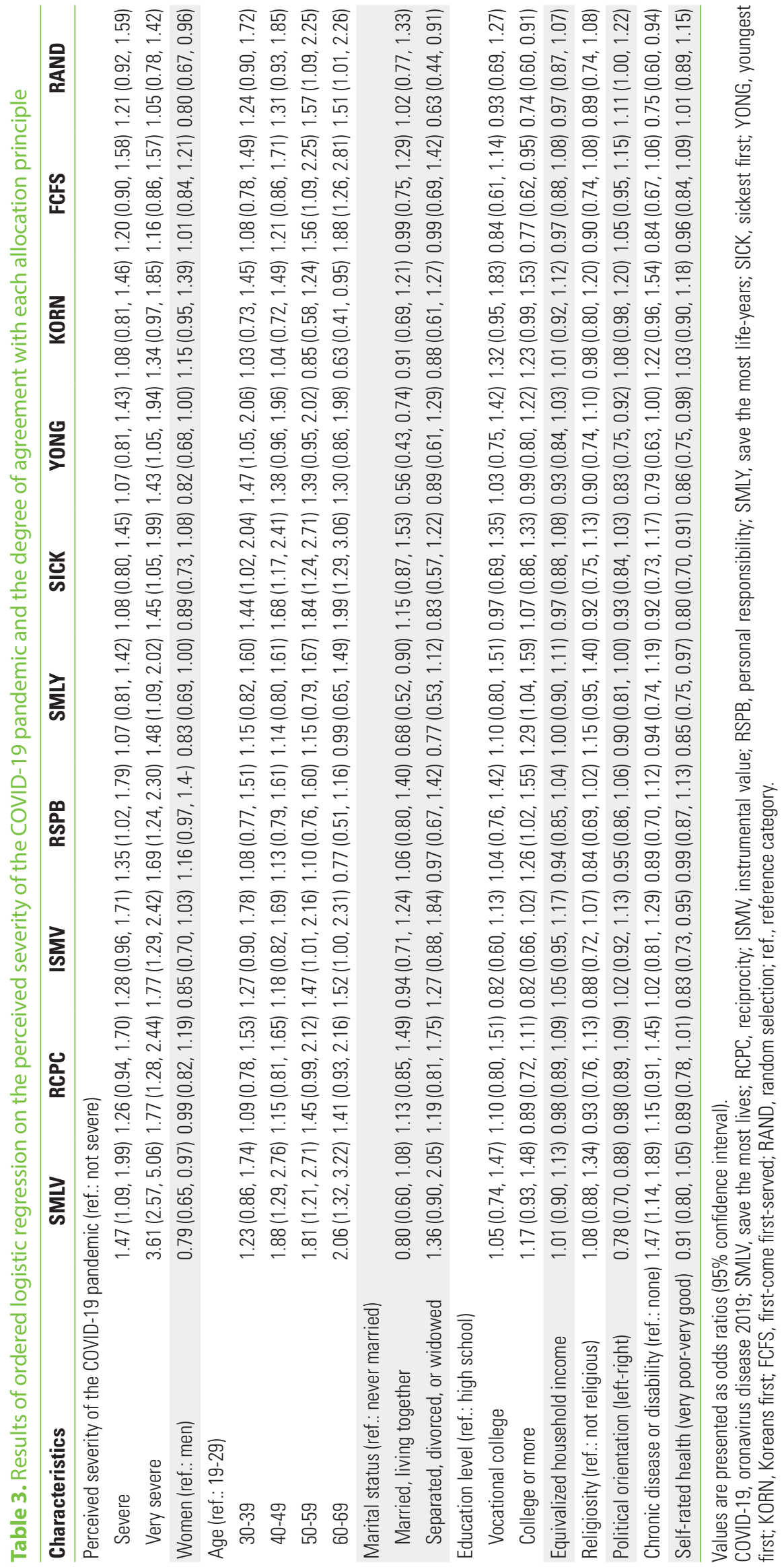


to be of considerable importance by ethicists, the public did not agree strongly with this principle. By contrast, while most ethicists believed that identity-based allocation cannot be morally justified, the public had an exceedingly high-level of preference for this principle. Principles based on prioritarianism, such as "sickest first" and "youngest first," were considered much more important by the public than by ethicists. There was a commonality between ethicists and the public in that relatively low importance was given to the principles based on egalitarianism in pandemics. While ethicists viewed "random selection" as fairer than "first-come, first-served," the public had the opposite view. There was no difference between the ethicists' recommendations and public preferences in that the "save the most lives" principle took the highest priority.

Higher perceived severity of the COVID-19 pandemic was associated with an increase in preferences for all principles except those based on egalitarianism and "Koreans first" (Table 3). When compared with the reference category of "not severe" in the perceived severity of the COVID-19 pandemic, the odds ratio of "very severe" for the preference of the allocation principles was highest for "save the most lives," followed in descending order by "reciprocity," "instrumental value," and "personal responsibility," with statistically significant differences at the significance level of $p$-value $<0.01$. In addition, the odds ratio of "not severe," "severe," and "very severe" showed a gradient in magnitude. The odds ratio of "very severe," compared with the reference category of "not severe," showed statistically significant differences at the $p$-value $<0.05$ level for "save the most life-years," "sickest first," and "youngest first." These results are in line with the views of ethicists who give higher priority to utilitarian principles and accepted principles based on social usefulness in a pandemic (Supplemental Material 5).

\section{DISCUSSION}

The main results of this study show that, in the situation of resource shortages in the COVID-19 pandemic, the general public of Korea agreed strongly with the principles of "save the most lives," "Koreans first," and "sickest first" as the main principles of resource allocation, but showed less agreement with egalitarian allocation principles. This indicates that there is a gap between public preferences and ethicists' recommendations on fair resource allocation principles in the COVID-19 pandemic. Another interesting finding is that higher perceived severity of the COVID-19 pandemic was associated with a high- er likelihood of agreeing with allocation principles based on utilitarianism and promoting and rewarding social usefulness, which is somewhat similar to the opinions of ethicists and may therefore help explain the expert-public gap.

These results are consistent with those presented in a United Kingdom study in that, contrary to the view of ethicists, the public had high preferences for allocation principles based on prioritarianism and "first-come, first-served" [11]. This implies that there may be some similarity in the moral intuition of the public across different countries. Of course, these similarities of public preferences alone do not provide an answer to the normative question of how scarce medical resources should be rationed in the COVID-19 pandemic. Rather, fair allocation principles could be sought through an iterative process of empirically exploring the normative standards proposed by ethicists and reconsidering the empirically obtained results in normative reasoning [28]. In that respect, the homogeneity of observed public preferences provides ethicists with a good prompt for moral inquiry to improve their arguments.

The differences between public preferences and ethicists recommendations may indicate that there are differences in moral values between the public and ethicists. However, another explanation for the difference lies in the method of this survey, a public opinion poll, which renders respondents likely to respond in an unreflective manner [29]. In this study, unlike ethicists' recommendations, the public gave a relatively high priority to the "youngest first" principle. However, several studies have shown that the tendency of the public to prefer the "youngest first" principle decreases when respondents are given a moral reasoning exercise or when a deliberative method is introduced to allow them to think in a reflective way [30,31]. Unlike the public, ethicists argue that the "first-come first-served" principle should not be used, because this principle can be thought of as unfair because it implies rationing through inconvenience [32]. However, this argument can only be reached after deep consideration. Thus, future research should investigate the moral preferences of the public after providing sufficient information and time to reflect on the topic. For this purpose, various deliberative democratic methods such as deliberative opinion polling, consensus conferences, and citizen juries could be used [33].

The differing views of the public and ethical experts suggest that governments should introduce and facilitate more dialogue and discussion in the process of developing rationing policies or guidelines. In times of crisis, such as the COVID-19 
pandemic, even a democratically elected government tends to rely heavily on unelected experts for policy-making [34]. Although experts may have better knowledge than the public about the scientific aspects of COVID-19, this is not always the case with value-laden matters such as rationing scarce medical resources. Therefore, to protect the ideals of democratic autonomy, governmental efforts to listen to and reflect the voices of the public are essential. From a policy perspective, the opinions and values of the public obtained through surveys could inform the development of rationing guidelines. As the public's moral preferences may also continue to change and evolve with their experiences of the impact of the COVID-19 pandemic [21], such a public survey should ideally be conducted on a periodic basis, rather than as a single-point survey, with possible implications for refining the rationing guidelines.

There are limitations in applying the results of this study in the development of rationing policies or guidelines. In this study, we investigated the public's preferences regarding allocation principles for scarce medical resources without specifying the types of resources. However, fair allocation principles may vary depending on the nature of the medical resources to be rationed. Not only is there a normative claim that fair allocation principles should differ according to the types of medical resources (e.g., vaccines vs. ventilators) [19], but there is also empirical evidence suggesting that the public supports different allocation principles depending on the types of medical resources $[35,36]$. Therefore, it is necessary to develop different rationing policies or guidelines according to the characteristics of resources. To do so, the results of this study are insufficient, and further research is needed to investigate the public's moral preferences for fair ways of rationing specific types of scarce medical resources.

This study has several other limitations. First, although proportional quota-based sampling based on age, gender, and region was used, the representativeness of the study subjects may not have been sufficiently secured since the subjects were drawn from panels registered with a company and not from random sampling. Differences in response rates by gender and age group are another factor that might reduce representativeness (Table S2 in Supplemental Material 1). Second, it is possible that the questionnaire did not measure precisely what we aimed to capture. For example, we expressed that resource allocation should be done through a "lottery" in the sense of treating people equally, but it is possible that the word "lot- tery" may have appeared to the public as if it were a way of making a flippant decision about an important issue. This possibility might explain the low degree of agreement with "random selection." Given the complexity of ethical considerations, future work should involve developing a better way of measuring each ethical principle with due attention to semantic and cognitive dimensions. Third, we did not directly compare preferences for allocation principles in general situations and pandemics within the same individual. Instead, we assumed that the preferences of those with low perceived severity of the COVID-19 pandemic would be indicative of preferences in general situations. The reason for using this method was that the impact of COVID-19 in the real world might be so strong that it would not be possible for each individual to respond to the statements on the questionnaire according to different degrees of perceived resource scarcity. Finally, although we controlled for many potential confounders to the extent possible in ordered logistic regression, it is still difficult to consider our results to be causal and robust.

Despite these limitations, this study has value in that it produced important information for the public discourse on how to ration scarce medical resources in the COVID-19 pandemic. In a pluralistic society where reasonable opinions coexist, many issues in healthcare and public health, which inevitably reflect different moral values and views on justice, should be resolved through reasoned public discussion and consensus. For a more informed, rational public discussion, valuable information on such issues is essential $[28,37]$. As there has been little empirical ethics research in the field of public health in Korea, more research of this kind on a variety of public health issues needs to be conducted. Regarding the specific context of this paper, studying the reasons for discrepancies between public preferences and ethicists' recommendations is an important avenue for future research.

\section{SUPPLEMENTAL MATERIALS}

Supplemental materials are available at https://doi.org/10. 3961/jpmph.21.333.

\section{CONFLICT OF INTEREST}

The authors have no conflicts of interest associated with the material presented in this paper. 


\section{FUNDING}

This work was supported by a National Research Foundation of Korea (NRF) grant funded by the Korean government (MSIT) (No. 0411-20200041).

\section{ACKNOWLEDGEMENTS}

None.

\section{AUTHOR CONTRIBUTIONS}

Conceptualization: JSL, YKD. Data curation: JSL, SK. Formal analysis: JSL. Funding acquisition: YKD. Methodology: JSL, YKD. Project administration: SK. Writing - original draft: JSL. Writing - review \& editing: JSL, SK, YKD.

\section{ORCID}

$\begin{array}{ll}\text { Ji-Su Lee } & \text { https://orcid.org/0000-0003-4269-7101 } \\ \text { Soyun Kim } & \text { https://orcid.org/0000-0002-7253-9318 } \\ \text { Young Kyung Do } & \text { https://orcid.org/0000-0001-5024-8264 }\end{array}$

\section{REFERENCES}

1. Ranney ML, Griffeth V, Jha AK. Critical supply shortages - the need for ventilators and personal protective equipment during the Covid-19 pandemic. N Engl J Med 2020;382(18):e41.

2. Kwon HK. Luckily, I bought my first public mask in 16 minutes. BabyNews; 2020 Mar 12 [cited 2021 May 26]. Available from: https://www.ibabynews.com/news/articleView.html?idxno= 83296 (Korean).

3. Park JY. The cumulative number of COVID-19 patients who died while waiting for hospitalization reached 8. Hankyoreh; 2020 Dec 18 [cited 2021 May 26]. Available from: https://www. hani.co.kr/arti/society/society_general/974970.html (Korean).

4. Maves RC, Downar J, Dichter JR, Hick JL, Devereaux A, Geiling $J A$, et al. Triage of scarce critical care resources in COVID-19 an implementation guide for regional allocation: an expert panel report of the task force for mass critical care and the American College of Chest Physicians. Chest 2020;158(1):212-225.

5. Lee KD. How should scarce healthcare resources be rationed during the COVID-19 pandemic? Korean J Med Ethics 2020; 23(3):145-169 (Korean).

6. Truog RD, Mitchell C, Daley GQ. The toughest triage - allocating ventilators in a pandemic. N Engl J Med 2020;382(21):19731975.

7. Emanuel EJ, Persad G, Upshur R, Thome B, Parker M, Glickman $A$, et al. Fair allocation of scarce medical resources in the time of Covid-19. N Engl J Med 2020;382(21):2049-2055.

8. Persad G, Wertheimer A, Emanuel EJ. Principles for allocation of scarce medical interventions. Lancet 2009;373(9661):423431.

9. Savulescu J, Persson I, Wilkinson D. Utilitarianism and the pandemic. Bioethics 2020;34(6):620-632.

10. Michalsen A, Vergano M, Quintel M, Sadovnikoff N, Truog RD. Epilogue: critical care during a pandemic-a shift from deontology to utilitarianism? In: Michalsen A, Sadovnikoff N, editors. Compelling ethical challenges in critical care and emergency medicine. Cham: Springer; 2020, p. 157-166.

11. Grover S, McClelland A, Furnham A. Preferences for scarce medical resource allocation: differences between experts and the general public and implications for the COVID-19 pandemic. Br J Health Psychol 2020;25(4):889-901.

12. Fallucchi F, Faravelli M, Quercia S. Fair allocation of scarce medical resources in the time of COVID-19: what do people think? J Med Ethics 2021;47(1):3-6.

13. Schicktanz S, Schweda M, Wynne B. The ethics of 'public understanding of ethics'--why and how bioethics expertise should include public and patients' voices. Med Health Care Philos 2012;15(2):129-139.

14. Baker R, Mason H, McHugh N, Donaldson C. Public values and plurality in health priority setting: what to do when people disagree and why we should care about reasons as well as choices. Soc Sci Med 2021;277:113892.

15. Persad G. Public preferences about fairness and the ethics of allocating scarce medical interventions. In: Li M, Tracer DP, editors. Interdisciplinary perspectives on fairness, equity, and justice. Cham: Springer; 2017, p. 51-65.

16. Rosenbaum L. Facing Covid-19 in Italy - ethics, logistics, and therapeutics on the epidemic's front line. N Engl J Med 2020; 382(20):1873-1875.

17. Lee IH. Distributive justice in the COVID-19 era. Bio Ethics Policy 2020;4(2):19-37 (Korean).

18. Huh JS, Kim KY. Legal issues pertaining to the triage of the COVID-19 pandemic. Bio Ethics Policy 2020;4(2):39-60 (Korean).

19. Kim J. Setting priorities for medical resource allocation of emergency treatment and vaccination for COVID-19 in South Korea. Bio Ethics Policy 2020;4(1):67-96 (Korean).

20. Park SH. Pandemic and distributive ethics of health-care re- 
sources. Humanit Stud East West 2020(59):261-291 (Korean).

21. Jin L, Huang $Y$, Liang $Y$, Zhang Q. Who gets the ventilator? Moral decision making regarding medical resource allocation in a pandemic. J Assoc Consum Res 2021;6(1):159-167.

22. Sharkey K, Gillam L. Should patients with self-inflicted illness receive lower priority in access to healthcare resources? Mapping out the debate. J Med Ethics 2010;36(11):661-665.

23. Cappelen AW, Norheim OF. Responsibility in health care: a liberal egalitarian approach. J Med Ethics 2005;31(8):476-480.

24. Rogge J, Kittel B. Who shall not be treated: public attitudes on setting health care priorities by person-based criteria in 28 nations. PLoS One 2016;11(6):e0157018.

25. Krütli P, Rosemann T, Törnblom KY, Smieszek T. How to fairly allocate scarce medical resources: ethical argumentation under scrutiny by health professionals and lay people. PLoS One 2016;11(7):e0159086.

26. Gollust SE, Saloner B, Hest R, Blewett LA. US adults' preferences for public allocation of a vaccine for coronavirus disease 2019. JAMA Netw Open 2020;3(9):e2023020.

27. Buckwalter W, Peterson A. Public attitudes toward allocating scarce resources in the COVID-19 pandemic. PLoS One 2020; 15(11):e0240651.

28. Knight R. Empirical population and public health ethics: a review and critical analysis to advance robust empirical-normative inquiry. Health (London) 2016;20(3):274-290.

29. Wikler D. Polls and focus groups in bioethics: the case of resource allocation. In: Lolas F, Agar L, editors. Interfaces be- tween bioethics and the empirical social sciences. Santiago: Pan American Health Organization; 2002, p. 91-98.

30. Johri M, Damschroder LJ, Zikmund-Fisher BJ, Kim SY, Ubel PA. Can a moral reasoning exercise improve response quality to surveys of healthcare priorities? J Med Ethics 2009;35(1):57-64.

31. Denburg AE, Ungar WJ, Chen S, Hurley J, Abelson J. Does moral reasoning influence public values for health care priority setting?: a population-based randomized stated preference survey. Health Policy 2020;124(6):647-658.

32. Eyal N, Romain PL, Robertson C. Can rationing through inconvenience be ethical? Hastings Cent Rep 2018;48(1):10-22.

33. Williams I, Dickinson $\mathrm{H}$, Robinson S. Rationing in health care: the theory and practice of priority setting. Bristol: Bristol University Press; 2012, p. 27-46.

34. Boschele M. COVID-19 science policy, experts, and publics: why epistemic democracy matters in ecological crises. OMICS 2020; 24(8):479-482.

35. Furnham A, Thomson K, McClelland A. The allocation of scarce medical resources across medical conditions. Psychol Psychother 2002;75(Pt 2):189-203.

36. Johri M, Damschroder LJ, Zikmund-Fisher BJ, Ubel PA. The importance of age in allocating health care resources: does intervention-type matter? Health Econ 2005l;14(7):669-678.

37. Salloch S, Vollmann J, Schildmann J. Ethics by opinion poll? The functions of attitudes research for normative deliberations in medical ethics. J Med Ethics 2014;40(9):597-602. 